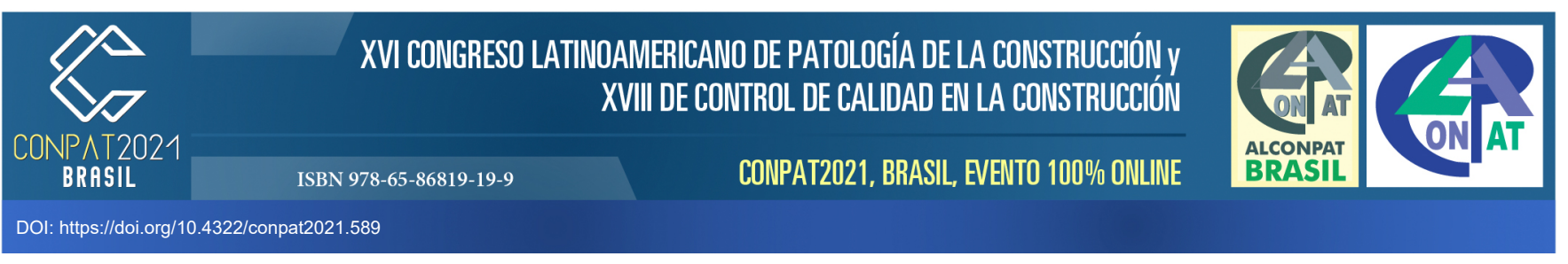

\title{
Aplicação da matriz GUT em manifestações patológicas de escolas públicas do centro potiguar
}

\author{
R. R. dos SANTOS ${ }^{1 *}$, J. C. de LIMA ${ }^{1}$, K. F. B. G. da SILVA ${ }^{1}$, \\ C. T. CRUZ ${ }^{2}$ \\ *Autor de Contacto: rodrigorodrigues9798@hotmail.com \\ ${ }^{1}$ Graduando em Engenharia Civil pela Universidade Potiguar, Brasil. \\ ${ }^{2}$ Doutora em Física da Matéria Condensada e Docente da Universidade Potiguar, Brasil.
}

\begin{abstract}
RESUMO
O crescente número de obras no setor da construção civil vem gerando uma necessidade de maior fiscalização dos problemas gerados em suas estruturas. $\mathrm{O}$ objetivo deste artigo foi identificar e analisar as principais anomalias encontradas em três escolas do centro potiguar, utilizando como método a matriz GUT (Gravidade, Urgência e Tendência) para priorização das manifestações patológicas. Foram realizadas visitas in loco com registros fotográficos e análise dos dados através da matriz GUT. Os resultados demonstraram que a aplicação da matriz foi efetiva para os danos encontrados, onde foram observados um número significativo de falhas devido a exposição e corrosão em armaduras.
\end{abstract}

Palavra-chave: Construção Civil; Escolas; Manifestações patológicas; Matriz GUT

\section{RESUMEN}

El creciente número de obras en el sector de la construcción ha generado la necesidad de una mayor supervisión de los problemas generados en sus estructuras. El objetivo de este artículo fue identificar 
y analizar las principales anomalías encontradas en tres escuelas del centro de Potiguar, utilizando como método la matriz GUT (Gravedad, Urgencia y Tendencia) para la priorización de las manifestaciones patológicas. Las visitas se realizaron in situ con registros fotográficos y análisis de datos a través de la matriz GUT. Los resultados mostraron que la aplicación de la matriz fue efectiva para los daños encontrados, donde se observó un número significativo de fallos por exposición y corrosión en la armadura.

Palabras clave: Construcción civil; Escuelas; Manifestaciones patológicas; Recuperación; Matriz GUT.

\section{ABSTRACT}

The growing number of works in the construction industry has generated a need for greater supervision of the problems generated in their structures. The objective of this paper was to identify and analyze the main anomalies found in three schools in the center of Potiguar, using as method the GUT matrix (Gravity, Urgency and Tendency) for prioritization of pathological manifestations. We conducted site visits with photographic records and data analysis using the GUT matrix. The results showed that the application of the matrix was effective for the damage found, where a significant number of failures due to exposure and corrosion in reinforcement were observed.

Keywords: Civil construction; Schools; Pathological manifestations; Recovery; GUT matrix.

\section{INTRODUÇÃO}

O setor da construção civil no Brasil vem crescendo e gerando um número maior de edificações. Brito (2017) mostra que cenário socioeconômico de países subdesenvolvidos, como o Brasil, faz com que as obras sejam construídas mais rapidamente e com um menor rigor sobre os processos realizados e materiais utilizados, causando uma queda na qualidade das edificações e em decorrência disso, são registrados com maior frequência manifestações patológicas em edificações 
de pouca idade, e de idades mais avançadas, expondo cada vez mais os problemas acontecidos in loco (QUEIROZ et al, 2020; FERRONATO, 2016; BRITO, 2017).

A utilização de materiais de qualidade inferior ou a falta de controle nos canteiros de obra faz com que as edificações venham a apresentar sintomas e doenças em sua estrutura. Patologia é o ramo da construção civil que estuda os sintomas, mecanismos de ocorrência, causas e origens dos defeitos que ocorrem na construção (QUEIROZ et al., 2020; FERRONATO,2016). Essas manifestações podem ser evitadas de diversas maneiras, uma delas é através da utilização do Programas de Controle de Qualidade, que consiste em um rígido controle nas etapas, desde os materiais utilizados na construção até os processos e serviços da construção (BRUM, 2003). Luduvico (2016) ainda ressalta que a patologia abrange toda as fases da construção civil, desde a elaboração do projeto até a execução da obra.

A manutenção das estruturas se faz necessária em diversas ocasiões, sendo prescritas de acordo com a NBR 14073:2014, para a elaboração de um manual de uso, operação e manutenção das estruturas que quando não seguidas e em associação da agressão dos agentes corrosivos externos, acabam gerando manifestações indesejadas nas estruturas, de modo a acarretar uma série de eventos que podem comprometer o estado limite de serviço (ELS) e em casos mais graves chegando a comprometer o estado limite último (ELU) da edificação. Para Queiroz et al. (2020) intervenções preventivas são de extrema importância para garantia da vida útil da edificação, e quanto mais cedo for realizado o diagnóstico dos problemas, mais cedo podem ser resolvidos, evitando assim danos maiores.

De acordo com Lucinda (2010), o Método GUT - Gravidade, Urgência e Tendência é uma ferramenta de priorização que fundamentada na gravidade, urgência e na tendência que os problemas podem representar para determinada estrutura. Este método utiliza números para dispor os graus a cada dano verificado e geralmente seu estudo é tendo em vista efeitos a médio e longo prazo. Nesse método, a Gravidade $(G)$ demonstra o dano potencial da manifestação e a importância da sua análise. A Urgência (U) define a necessidade da tomada de decisão para a resolução da anomalia. Já a Tendência (T) explicita o agravamento daquele problema ao longo do tempo se não tratado adequadamente. (MARTINS et al. 2017)

Segundo Nóbrega (2019), os problemas patológicos identificados em diversas edificações são gerados em sua maioria por falta de planejamento, má execução e falta de manutenção ao longo do tempo, além dos fatores ambientais em que a estrutura se encontra exposta. Esses problemas patológicos podem se manifestar no curto prazo logo após a finalização da obra ou no longo prazo, podendo aparecer anos depois de sua finalização (BRUM, 2003).

A presença de manifestações patológicas gera uma redução da vida útil da estrutura, visto que as patologias estão diretamente ligadas ao desempenho dos materiais utilizados, planejamento, execução e mão de obra qualificada (TAGUCHI, 2010; FERRONATO, 2016). Para que essas manifestações patológicas existentes tenham o tratamento adequado, faz-se necessária uma análise criteriosa, onde é preciso identificar suas possíveis causas, chegando a sua origem, possibilitando assim a aplicação do tratamento adequado (FERRONATO, 2016).

Este artigo tem como objetivo identificar e analisar as principais manifestações patológicas, utilizando a matriz GUT (Gravidade, Urgência e Tendência), em três escolas do centro potiguar.

\section{METODOLOGIA}


O presente estudo foi realizado em três instituições de ensino na região centro do estado do Rio Grande do Norte no qual foram identificadas e analisadas as principais manifestações patológicas, utilizando como método a matriz GUT (Gravidade, Urgência e Tendência) como priorização das anomalias.

Figura 1: Metodología

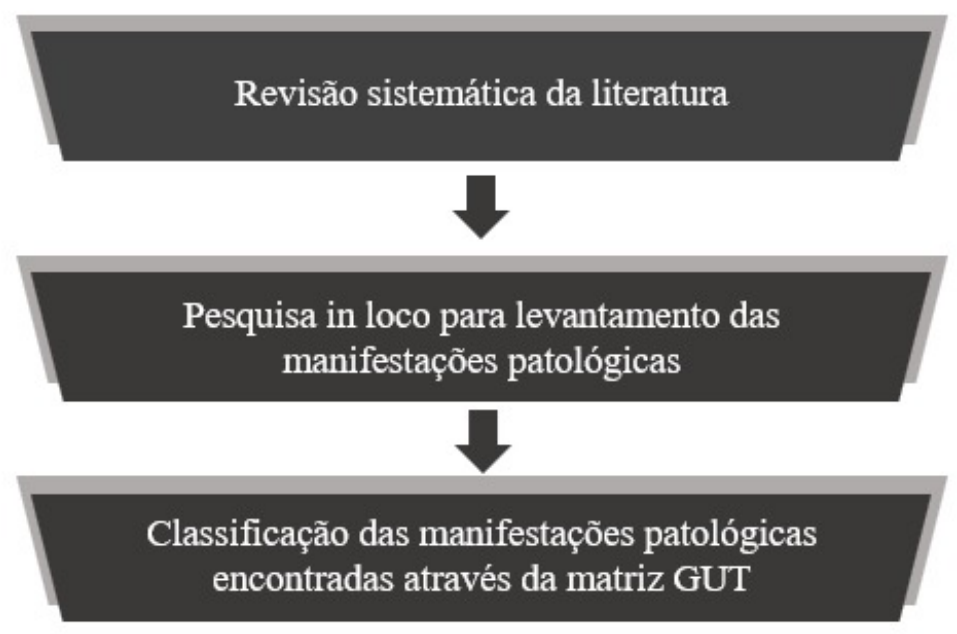

Fonte: Autores

A primeira instituição foi chamada genericamente de $\mathrm{X}$ e está situada na cidade de Bodó; a segunda e a terceira, Y e Z, estão situadas na cidade de Macau. A metodologia foi realizada em 4 etapas, conforme ilustrado na Figura 1.

$\mathrm{Na}$ primeira etapa foi realizada a revisão bibliográfica sobre manifestações patológicas nas edificações e utilização da matriz GUT, objetivando embasar a escrita e auxiliar nas etapas posteriores do estudo.

$\mathrm{Na}$ segunda etapa foi realizada uma visita técnica em cada instituição onde foi executada uma inspeção visual de caráter prévio com o intuito de realizar um levantamento das manifestações patológicas presentes na estrutura, para tanto foram realizados registros fotográficos das áreas mais degradadas. 
Tabela 1: Matriz GUT

\begin{tabular}{|c|c|c|c|c|}
\hline \multirow{2}{*}{ Pontos } & Gravidade & Urgência & Tendência & Prejuizos de nenhuma \\
\cline { 2 - 5 } & decisão ser tomada & $\begin{array}{c}\text { Necessidade de } \\
\text { tomada de decisão }\end{array}$ & $\begin{array}{c}\text { Evolução do problema caso } \\
\text { nenhuma decisão seja tomada }\end{array}$ & G $\mathbf{x}$ U T \\
\hline $\mathbf{5}$ & Extremamente graves & Imediatamente & Agravamento imediato & $5 \times 5 \times 5=125$ \\
\hline $\mathbf{4}$ & Muito Graves & Urgentemente & Agravamento a curto prazo & $4 \times 4 \times 4=64$ \\
\hline $\mathbf{3}$ & Graves & $\begin{array}{c}\text { O quanto antes } \\
\text { possivel }\end{array}$ & Agravamento em médio prazo & $3 \times 3 \times 3=27$ \\
\hline $\mathbf{2}$ & Pouco Graves & Mediana & Agravamento em longo prazo & $2 \times 2 \times 2=8$ \\
\hline $\mathbf{1}$ & Sem gravidade & Pouca & Não há indicios de que irá se & $1 \times 1 \times 1=1$ \\
\hline
\end{tabular}

Fonte: Adptado de Verzola et al. (2014)

Em seguida, na terceira etapa, fez-se um levantamento das anomalias presentes e em seguida foi aplicada a metodologia da Matriz GUT - Gravidade, Urgência e Tendência, apresentada na Tabela 1, também é conhecida como Matriz de Prioridades, a qual auxilia na priorização de resolução de problemas. De acordo com Daychoum (2012), no critério Gravidade são classificados os efeitos em caso de nenhuma providência ser tomada acerca do problema; já no quesito Urgência avalia-se o quão necessário se faz tomar uma decisão para resolver o problema encontrado, e no critério Tendência pode ser avaliada a evolução que pode acontecer com o problema encontrado. Cada critério para avaliação da matriz GUT recebe uma pontuação de 1 a 5 , onde 1 é menos grave e 5 mais grave, sendo o resultado a multiplicação da pontuação atribuída a cada um dos critérios. Segundo de Azevedo Ferreira et al. (2014) e Braga et al. (2019) a método GUT é de extrema importância e utilidade para resolução de problemas, visto que é possível classificar os problemas encontrados de acordo com sua gravidade e assim traçar as melhores estratégias para solução.

\section{RESULTADOS E DISCUSSÕES}

\subsection{Escola X}

Na escola X, foram identificadas manifestações patológicas no banheiro da escola e no pátio. Verifica-se na Figura 2 o desplacamento cerâmico nas paredes, que pode ter sido ocasionado por má execução e/ou utilização de materiais de baixa qualidade, prejudicando assim a aderência entre a placa cerâmica e a superfície. Na Figura 3 nota-se a degradação da pintura com a presença de mofo e agentes biológicos, possivelmente ocasionado por falha ou ausência na impermeabilização da laje, onde possivelmente ocorre a infiltração de águas de origem pluviais. A não correção desse problema pode ocasionar danos maiores, visto que o agravamento pode chegar na armadura da laje e assim comprometer a estabilidade de estrutura. 
Figura 2: Desplacamento cerâmico

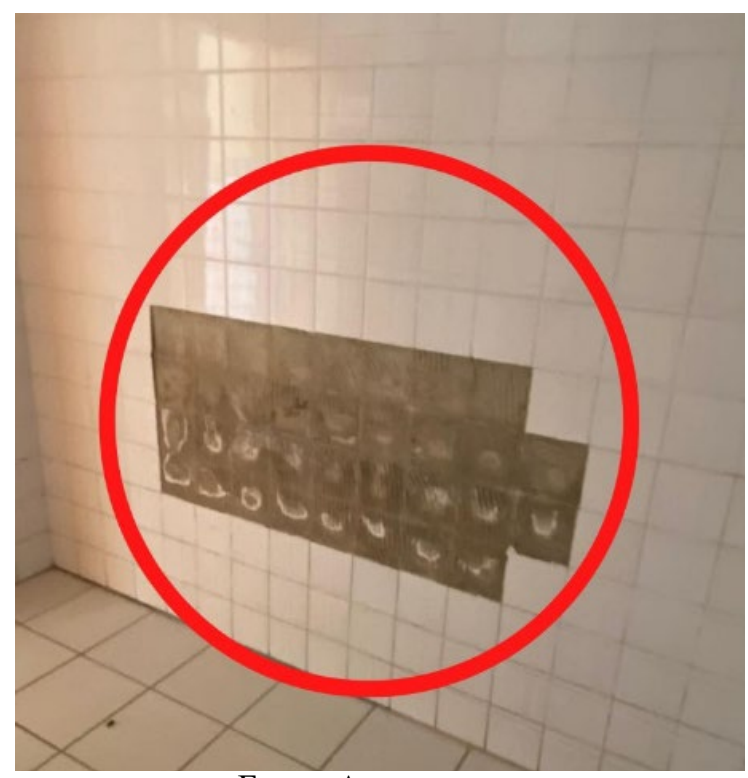

Fonte: Autores
Figura 3: Infiltração na laje

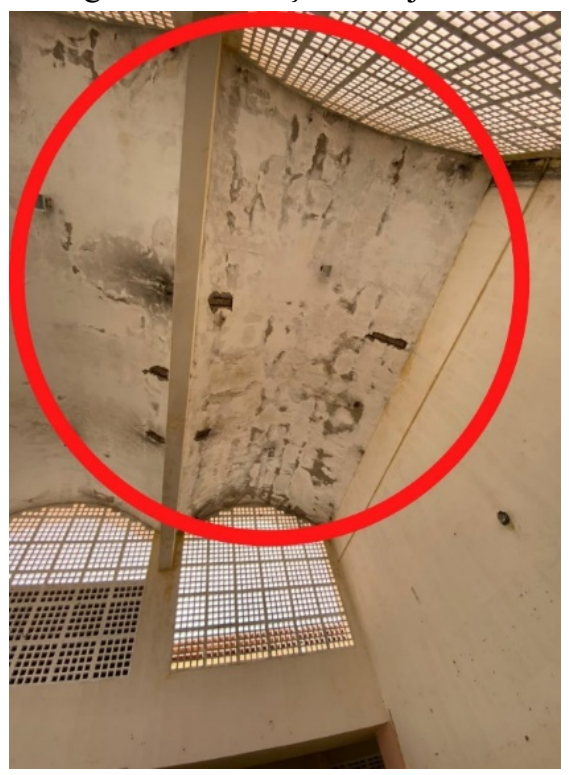

Fonte: Autores

Tabela 2: Avaliação utilizando a Matriz GUT

\begin{tabular}{|c|c|c|c|c|c|c|}
\hline Escola & Foto & Descrição & G & U & T & GUT \\
\hline $\mathrm{X}$ & 2 & Desplacamento cerâmico & 3 & 2 & 2 & 12 \\
\hline $\mathrm{X}$ & 3 & Degradação da pintura por infiltração & 4 & 4 & 3 & 48 \\
\hline
\end{tabular}

Fonte: Autores

$\mathrm{Na}$ avaliação das manifestações patológicas, como visto na Tabela 2, o desplacamento cerâmico da Figura 2 foi classificado de uma maneira geral como não sendo um problema que requer imediata resolução, porém se fazem necessárias medidas que evitem o agravamento da situação. As manifestações da Figura 3 foram classificadas como as mais graves e urgentes da escola em questão com uma pontuação de 48 na matriz GUT, sendo levado em consideração os riscos que os alunos da escola estão sujeitos em caso de um possível colapso da estrutura danificada pelas manifestações patológica.

Para o desplacamento cerâmico uma possível solução é a substituição do revestimento presente. Para as manifestações da degradação da pintura por infiltração, a sugestão é que a pintura seja substituída aplicando uma camada impermeabilizante na laje, visando proteger a laje da infiltração que pode estar ocasionando as manifestações encontradas.

\subsection{Escola Y}

$\mathrm{Na}$ escola $\mathrm{Y}$ foram analisadas as manifestações patológicas encontradas nos pilares de suporte do reservatório de abastecimento da instituição, consideradas as mais críticas. 
Na Figura 4 observa-se a exposição e oxidação da armadura possivelmente devido ao uso de materiais inadequados que causaram um ancoramento frágil entre a matriz cimentícia e a armadura, fazendo com que a camada de concreto se desprenda da armadura. A não correção pode gerar danos maiores e comprometer a estabilidade da estrutura, podendo chegar a causar o colapso da estrutura.

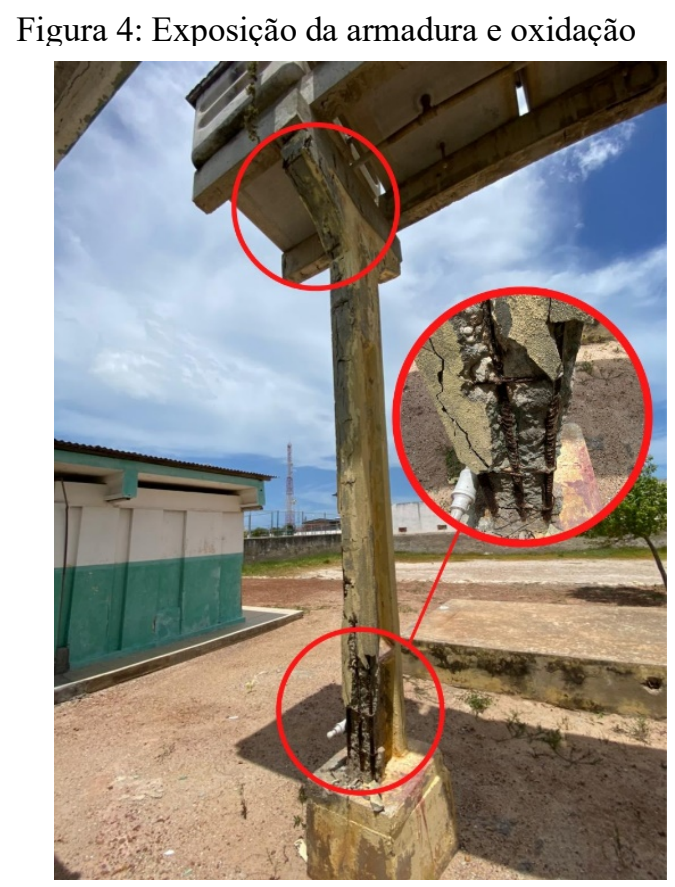

Fonte: Autores

Na Figura 5 observa-se também uma exposição da armadura e fissuras ao longo de toda a estrutura. Essas fissuras podem ter sido geradas pela falta de técnicas adequadas durante a execução do projeto juntamente com a utilização de materiais inadequados. O não tratamento dessas manifestações podem levar a exposição total da armadura causando uma possível corrosão, de forma que a estabilidade da estrutura seja comprometida. 
Figura 5: Exposição da armadura e fissuras

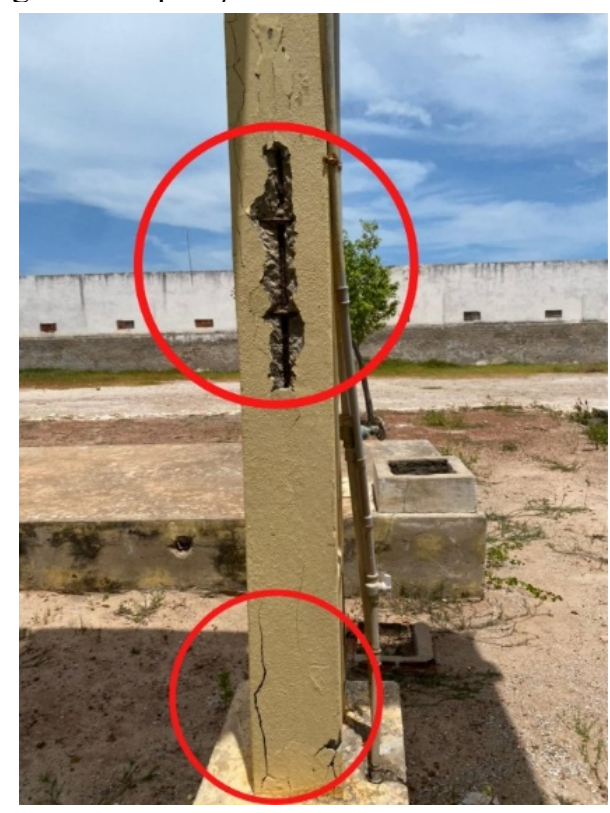

Fonte: Autores

Tabela 3: Avaliação utilizando a Matriz GUT

\begin{tabular}{|c|c|c|c|c|c|c|}
\hline Escola & Foto & Descrição & G & U & T & GUT \\
\hline $\mathrm{Y}$ & 4 & Exposição da armadura e corrosão & $\mathbf{5}$ & 5 & 4 & 100 \\
\hline $\mathrm{Y}$ & 5 & Exposição da armadura e fissuras & 4 & 4 & 3 & 48 \\
\hline
\end{tabular}

Fonte: Autores

As manifestações patológicas foram classificadas e tiveram suas pontuações expostas na Tabela 3. As exposições e corrosão de armadura da figura 4 foram tratadas como as mais urgentes da escola e que necessita de intervenção imediata com uma pontuação de 100 na matriz GUT, esses riscos foram determinados baseado no estado de deterioração das estruturas analisadas. As fissuras e exposição da armadura mais sutis na Figura 5 foram consideradas pouco graves, mas com necessidade de intervenção o mais breve possível para se evitar o agravamento da situação.

Para a corrosão e exposição da armadura foi apresentado como possível solução a aplicação de produto anticorrosivo e reposição da área de concreto degradada, cabe salientar que se deve realizar um estudo mais profundo a respeito do estado atual da armadura da estrutura e após verificação tomar as necessidades cabíveis ao seu estado. Para a exposição mais suscinta e fissuras, foi sugerido também para remoção do material residual e reposição da área de concreto perdida juntamente a aplicação de produto anticorrosivo.

\subsection{Escola Z}

$\mathrm{Na}$ escola $\mathrm{Z}$, foram identificadas anomalias consideradas críticas na região externa das salas de aula e no pátio da escola.

Nas Figuras 6 e 7, é possível identificar a degradação e desplacamento do reboco da edificação, causando uma exposição da alvenaria e da armadura dos pilares de extremidade, que pode ter sido provocado pela má qualidade nos materiais na execução, ou pela ausência de chapisco para melhor aderência do reboco. Observa-se também a utilização de material argiloso. 
Figura 6: Exposição da alvenaria e do com alto nivel de oxidação dos pilares.

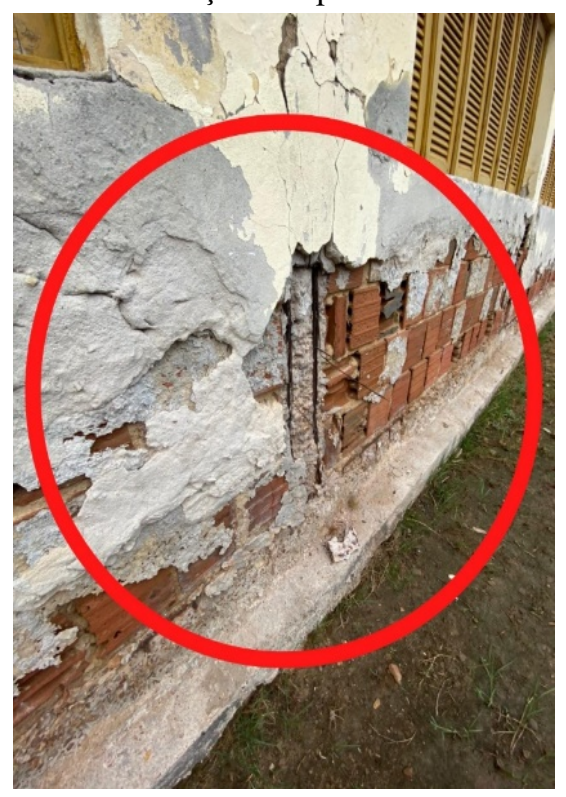

Fonte: Autores
Figura 7: Exposição da alvenaria e do com alto nivel de oxidação dos pilares.

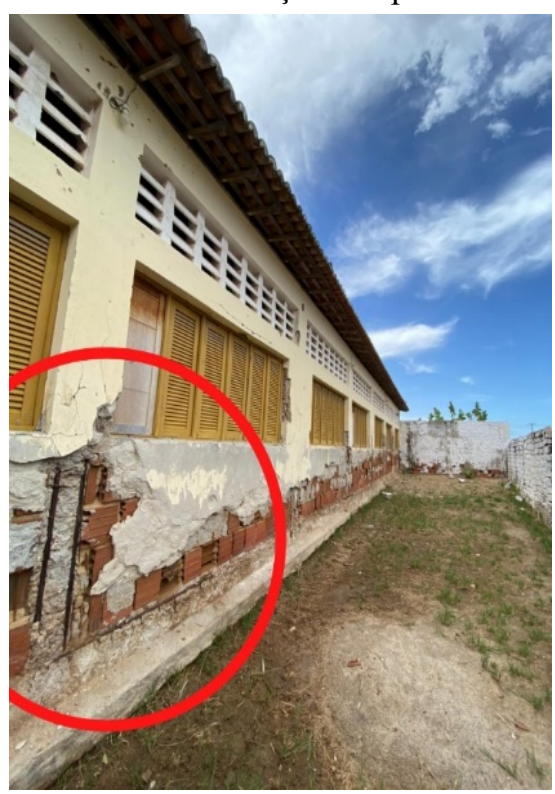

Fonte: Autores

Na Figura 8, foi observado a degradação da estrutura, exibindo um material argiloso que pode ter sido utilizado na execução da edificação, não sendo um material indicado para a matriz cimentícia, podendo causar graves problemas quando exposto a umidades a curtos e longos períodos.

Figura 8: Fissuração e degradação da estrutura.

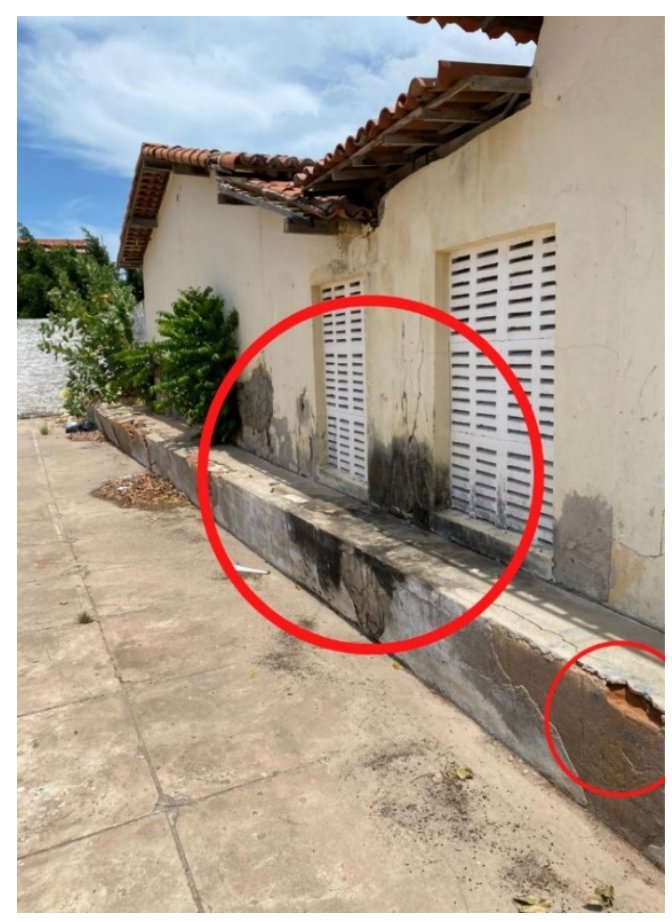

Fonte: Autores 
Tabela 4: Avaliação utilizando a Matriz GUT

\begin{tabular}{|c|c|c|c|c|c|c|}
\hline Escola & Foto & Descrição & G & U & T & GUT \\
\hline Z & 6 e 7 & $\begin{array}{c}\text { Exposição da alvenaria e da armadura } \\
\text { dos pilares de extremidade }\end{array}$ & 4 & 3 & 4 & 48 \\
\hline Z & 8 & $\begin{array}{c}\text { Degradação da pintura, fissuração } \\
\text { generalizada por utilização de } \\
\text { material inadequado }\end{array}$ & 3 & 2 & 2 & 12 \\
\hline
\end{tabular}

Fonte: Autores

Na avaliação das manifestações patológicas, como visto na Tabela 4, a exposição da alvenaria e da armadura dos pilares de extremidade nas Figuras 6 e 7 foram tratadas como as mais urgentes da escola com uma pontuação de 60 na matriz GUT, sendo essa pontuação atribuída ao risco que a infiltração de água em um médio período de tempo pode oferecer aos pilares da edificação. A fissuração generalizada causada por uso inadequado foi considerada grave devido ao risco de poder causar um desplacamento do reboco, sendo adequado intervenção o quanto antes para retirada do material e reposição de um material adequado.

Para exposição da alvenaria e da armadura dos pilares de extremidade foi apresentada como solução a retirada do material residual de argamassa e aplicação de chapisco seguida de um novo material com matriz cimentícia para proteção da alvenaria, e para os pilares sendo necessária a aplicação de um produto anticorrosivo e restituição da camada de proteção. Sendo inevitável um estudo mais aprofundado sobre o estado atual da armadura dos pilares, e após a análise, tomar as necessidades cabíveis ao seu estado. Para as fissuras identificadas pelo uso de material inadequado foi sugerido a remoção total do material e restituição da área de argamassa com material adequado.

\section{CONCLUSÕES}

É possível concluir que a aplicação da matriz GUT foi efetiva nas principais manifestações patológicas encontradas nas três escolas do centro potiguar, permitindo traçar um plano de recuperação mais direcionado e focado em começar por onde há maior prioridade.

$\mathrm{Na}$ escola $\mathrm{X}$ foram verificadas anomalias de degradação da pintura por infiltração e desplacamento cerâmico. A degradação da pintura foi tratada como grave e tomada de decisão urgente e agravamento a médio prazo, chegando a 48 pontos na matriz GUT.

Na escola Y, foram constatados danos de exposição e corrosão em armadura e também fissuras e exposição da armadura. A exposição e corrosão foram pontuadas como extremamente graves e de necessidade de intervenção imediata e com agravamento a curto prazo, atingindo a pontuação de 100 pontos na matriz GUT, já as fissuras e exposição de armadura expostas obtiveram 48 pontos no GUT.

Por fim, foi verificado na escola $Z$ a presença da exposição da alvenaria e da armadura dos pilares de extremidade foram consideradas graves e de necessidade de intervenção o quanto antes possível com agravamento a curto prazo pontuando 48 na matriz GUT. Ainda na escola $Z$ foi verificada degradação da pintura e fissuração generalizada pela utilização de material inapropriado, estes danos foram considerados graves e com medidas a serem assim que possível com agravamento a logo prazo, com um total de 12 pontos.

É válido salientar que as sugestões de reparo das edificações são baseadas no método de inspeção visual, estudos e ensaios mais específicos e aprofundados se fazem necessários para definir com exatidão a situação das edificações e manifestações patológicas encontradas. 
Com isso, o presente trabalho atingiu aos objetivos propostos quando as manifestações analisadas foram classificadas e identificadas através do método da matriz GUT. 


\section{REFERÊNCIAS}

ASSOCIAÇÃO BRASILEIRA DE NORMAS TÉCNICAS. NBR 14037: Diretrizes para Elaboração de Manuais de Uso, Operação e Manutenção das Edificações - Requisitos para Elaboração e Apresentação dos Conteúdos. Rio de Janeiro, p.16. 2011 (versão corrigida: 2014)

Braga, I. C., Brandão, O. F. S., Ribeiro, F. R. C., Diógenes, A. G. (2019). “Aplicação da Matriz GUT na análise de manifestações patológicas em construções históricas”. Revista ALCONPAT, 9(3), pp. 320 - 335, DOI: http://dx.doi.org/10.21041/ra.v9i3.400

Brito, T. F. “Análise de manifestações patológicas na construção civil pelo método Gut: Estudo de caso em uma instituição pública de ensino superior”. 2017. 77 f. Monografia (Especialização) - Curso de Engenharia Civil, Centro de Tecnologia, Universidade Federal da Paraíba, João Pessoa, 2017. Cap. 1.

Brum, F. S, Oliveira, R. S., Soares, M. T., Carmo, I. O. P. "Patologia das construções”. (Laboratório de Materiais de Construção Civil, Centro de Tecnologia, UFSM).

De Azevedo Ferreira, Maxwel; De Oliveira, Ualison Rébula; De Almada Garcia, Pauli Adriano. Quatro ferramentas administrativas integradas para o mapeamento de falhas: um estudo de caso. Revista Uniabeu, v. 7, n. 16, p. 300-315, 2014.

Daychoum, Merhi. “40+ 20 ferramentas e técnicas de gerenciamento”. Brasport, 2018.

Delgado, R. C. O. B. Nobrega, p. N. "Patologias na construção civil - Análise das principais manifestações patológicas em residências do município de Paraú-RN”. 2019 - Trabalho de conclusão de curso - universidade federal rural do semiárido - UFERSA

Ferronato, Angélica. "Estudo das principais manifestações patológicas encontradas nas estruturas em habitações residenciais de interesse social”. 2017.

Martins, N, Pessoa, R., Nascimento, R. (2017). Priorização na Resolução de Manifestações Patológicas em Estruturas de Concreto Armado: Método GUT. Revista de Engenharia e Pesquisa Aplicada, 2(3). https://doi.org/10.25286/repa.v2i3.707

De Oliveira, L. K M. Carneiro, F. Y. S. Fernandes, A. C. A. F. De Oliveira, A. D. Marinho, R. O. "Utilização da matriz gut na priorização de manifestações patológicas em sistemas prediais hidraúlicos e sanitários”. Congresso Técnico Científico da Engenharia e da Agronomia, 2018.

Luduvico, T. S. “Desempenho a estanqueidade à água: interface janela e parede”. Dissertação de Mestrado, Universidade Federal de Santa Maria, Santa Maria, 2016. Disponível em: https://repositorio.ufsm.br/handle/1/7928.

Martins, N., Pessoa, R., Nascimento, R. Priorização na Resolução de Manifestações Patológicas em Estruturas de Concreto Armado: Método GUT, Revista de Engenharia e Pesquisa Aplicada, 2017. 2 (3): 139-147.

Nazario, Daniel. "Manifestações das patologias construtivas nas edificações públicas da rede municipal de Criciúma: Inspeção dos sete postos de saúde”. 2012. 
De Queiroz, A. B. R. Marques, V. D. Cruz, C. P. T. Dos Santos, K. F. Dos Santos, R. R. Lucena, M. M. "Análise de manifestações patológicas na balaustrada da Av. Getúlio Vargas em Natal/RN: Um estudo de caso". Anais do Congresso Brasileiro de Patologia das Construções - CBPAT, Fortaleza, 2020.

Taguchi, M. K. "Avaliação e qualificação das patologias das alvenarias de vedação nas edificações”. 2010. 64 f. Dissertação (Mestrado) - Curso de Engenharia Civil, Setor de Tecnologia da Universidade Federal do Paraná, Universidade Federal do Paraná, Curitiba, 2010. Cap. 1.

Verzola, Simone Nunes; Marchiori, Fernanda Fernandes; Aragon, José Octávio. "Proposta de lista de verificação para inspeção predial x urgência das manutenções". Encontro Nacional de Tecnologia do Ambiente Construído, XV ENTAC, Maceió: Alagoas (Brasil), p. 1226-1235, 2014. 